\title{
ARTIGOS
}

Submetido em 01.02.2020. Aprovado em 13.10.2020.

Avaliado pelo processo double-blind review. Editor científico convidado: Tobias Coutinho Parente

Versão traduzida | DOI: http://dx.doi.org/10.1590/So034-759020210602x

\section{SUCESSÃO EXITOSA: O CONTEXTO DO ENTORNO E O PLANO DE SUCESSÃO}

\author{
Successful succession: The role of the environment and the succession plan \\ Sucesión exitosa: El rol del entorno y el plan de sucesión
}

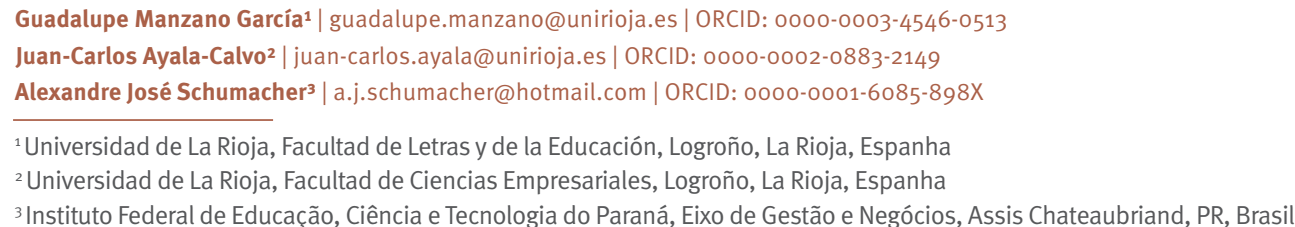

\section{RESUMO}

A literatura sobre sucessão continua desarticulada, e apenas nos últimos anos começam a surgir estudos que oferecem uma visão global dos fatores que contribuem para que o processo de sucessão seja exitoso. Com base em uma amostra de 230 empresários do agronegócio do Estado do Paraná, utilizamos um desenho de estudo de distanciamento temporal para comprovar até que ponto o plano de sucessão, o entorno familiar, o entorno organizacional e o entorno econômico podem prever o êxito da sucessão. Os resultados mostram que a variável que mais contribuiu para o êxito do processo de sucessão foi aquela sobre a qual a empresa tem menos controle: o entorno econômico. Os resultados sugerem que, para garantir sua sobrevivência, as empresas familiares devem planejar a sucessão e fomentar o desenvolvimento de contextos familiares e organizacionais que incentivem os novos líderes a querer assumir a gestão da empresa familiar.

PALAVRAS-CHAVE | PME familiares, sucessão exitosa, entorno, plano de sucessão, harmonia familiar.

\section{ABSTRACT}

Succession literature remains non-cumulative and disjointed, and studies are only just appearing that offer an overall view of the factors that make the succession process a success. Our study was based on a sample of 230 agribusiness entrepreneurs from the state of Paraná (Brazil). We used a time-lagged design to test the extent to which the succession plan, the family environment, the organizational environment and the economic environment are able to predict succession success. Our results showed that the variable that contributed most to the success of the succession process is one that the firm has the least control over: the economic environment. The findings suggest that in order to guarantee survival family-run enterprises must plan for succession and foster the development of a family and organizational context that encourages new leaders to want to take over the management of the family business.

KEYWORDS I Family SMES, successful succession, environment, succession plan, family harmony.

\section{RESUMEN}

La literatura sobre sucesión sigue desarticulada y apenas hay estudios que ofrezcan una visión global de los factores que ayudan a que el proceso de sucesión sea un éxito. Nuestro estudio se basó en una muestra de 230 emprendedores del agronegocio del estado de Paraná (Brasil). Usamos un diseño de tiempo retardado para comprobar hasta qué punto el plan de sucesión, el entorno familiar, el entorno organizacional y el entorno económico pueden predecir el éxito de la sucesión. Los resultados mostraron que la variable que más contribuyó al éxito del proceso de sucesión fue aquella sobre la que la empresa tiene menos control: el entorno económico. Los hallazgos sugieren que, para garantizar su supervivencia, las empresas familiares deben planificar la sucesión y fomentar el desarrollo de contextos familiares y organizacionales que alienten a los nuevos líderes a desear asumir la gestión de la empresa familiar.

PALABRAS CLAVE I Pymes familiares, sucesión exitosa, entorno, plan de sucesión, armonía familiar. 


\section{INTRODUÇÃO}

É extensa a literatura que indica o importante papel desempenhado por pequenas e médias empresas (PMEs) no crescimento econômico, emprego e exportações de países em desenvolvimento (Nikolić, Jovanović, Nikolić, Mihajlović, \& Schulte, 2018). As PMEs são, de longe, o tipo de negócio mais comumente encontrado em qualquer economia do mundo, especialmente em economias em desenvolvimento (Pessotto, Costa, Schwinghamer, Colle, \& Corte, 2019). Por outro lado, estima-se que entre $90 \%$ e $98 \%$ das PMEs nas economias desenvolvidas ou em desenvolvimento sejam geridas por famílias (Inter American Development Bank, United Nations, \& Organization of American States, 2011). O papel da PME familiar é, portanto, essencial para as perspectivas econômicas e sociais das nações desenvolvidas e em desenvolvimento, uma vez que a maior parte da riqueza, tanto nas economias nacionais quanto na economia global como um todo, é produzida por esse tipo de organização. Uma das economias em desenvolvimento em que as PMEs familiares são mais importantes é o Brasil (Organização para Cooperação e Desenvolvimento Econômico, 2018). Em 2017, as PMEs brasileiras representavam 98.5\% do total de empresas do país, empregando $41 \%$ da força de trabalho e gerando $27 \%$ do PIB.

Um dos mais importantes desafios enfrentados por PMEs familiares envolve o processo de sucessão do Chief Executive Officer - CEO. No Brasil, esse processo é particularmente importante para as empresas do agronegócio familiares pequenas e médias, por duas razões intimamente correlacionadas. Primeiramente, estima-se que $70 \%$ das empresas do agronegócio familiares pequenas e médias não sobreviverão à geração fundadora inicial, e apenas $5 \%$ durarão por três gerações (Schumacher, 2015). Em segundo lugar, processos fracassados de sucessão podem ser uma das causas dos níveis significativos de migração do campo para a cidade. Essa migração tem levado a uma drástica diminuição da população rural nos últimos 30 anos, e pode estar colocando a sobrevivência das empresas do agronegócio familiares pequenas e médias em risco (Foguesatto, Mores, Kruger, \& Costa, 2020).

Muitos fatores são utilizados para explicar a falta de sucessores nas empresas do agronegócio familiares pequenas e médias brasileiras (Foguesatto et al., 2020; Morais, Borges, \& Erlaine, 2017; Pessotto et al., 2019), tais como: preferências pessoais, a lucratividade da empresa do agronegócio, o tipo e o local da empresa do agronegócio, o sistema de posse da área territorial, direitos de herança, níveis de educação formal, gênero, habilidades e conhecimentos práticos, relações intergeracionais, tecnologia etc. Esses fatores são semelhantes aos que têm sido ligados ao êxito ou fracasso de processos sucessórios em empresas do agronegócio pequenas e médias em países desenvolvidos (May, Arancibia, Behrendt, \& Adams, 2019). De acordo com a Organização das Nações Unidas para a Alimentação e a Agricultura (FAO) (Garner \& Campos, 2014), no entanto, a importância de cada um desses fatores pode variar, dependendo do contexto do país em questão. Assim, em países em desenvolvimento, como 0 Brasil, a influência desses ou outros fatores no êxito do processo sucessório pode diferir em função da maior dificuldade que as empresas do agronegócio familiares pequenas e médias desses países enfrentam para acessar sistemas de proteção social, fontes de financiamento, capacitação, a utilização de novas tecnologias etc. (Garner \& Campos, 2014). Ademais, segundo Minichilli, Nordqvist, Corbetta, e Amore (2014), além do contexto nacional (contexto macro), as circunstâncias em torno do sucessor, tais como sua família ou o agronegócio familiar (contexto micro), também são significativas no êxito do processo de sucessão. Tal importância reside no fato de que o entorno micro é fundamental no processo de socialização dos potenciais sucessores, e pode afetar a harmonia familiar e os comportamentos dos sucessores, bem como seu desejo de dirigir o agronegócio familiar.

A maior parte dos trabalhos realizados no Brasil sobre sucessão em empresas do agronegócio familiares pequenas e médias tem seguido a abordagem "baseada em fator”, na qual a sucessão exitosa é resultado de uma combinação de fatores individuais (quantificáveis e observáveis) com influência positiva ou negativa (Pes- 
sotto et al., 2019). Até onde sabemos, no entanto, não há estudos que incluam os fatores latentes (variáveis não observáveis diretamente) com influência de longo prazo sobre a socialização do sucessor para fins de definição de sucessão exitosa, e relacionados tanto ao contexto macro (entorno econômico) quanto ao micro (família, organização e plano sucessório).

A maioria dos estudos anteriores mediram o êxito do processo de sucessão utilizando medidas objetivas e subjetivas quase sempre focadas em variáveis econômicas (Ayala-Calvo, Manzano-García, \& Schumacher, 2019). Seu principal ponto negativo, porém, é que não levaram em consideração o que acontece com a harmonia familiar ao fim do processo sucessório. Pesquisas anteriores sugerem que o êxito e a sobrevivência da empresa estão relacionados a aspectos não econômicos do negócio (Sharma, 2004). Nosso modelo, portanto, se baseia na ideia de que o êxito do processo sucessório é um construto que deve levar em conta tanto os aspectos econômicos quanto a harmonia familiar, tais como: a necessidade de pertencimento, afeição ou confiança, o espírito de ser útil, e/ou a consciência do bem-estar dos outros (Kavikondala et al., 2016).

Com base nos comentários anteriores, o principal objetivo de nosso trabalho é propor um modelo que ofereça uma melhor compreensão das principais variáveis que condicionam a sucessão exitosa do líder (CEO) em empresas do agronegócio familiares pequenas e médias, e a importância relativa de cada variável. Examinamos especificamente como os contextos econômico, organizacional e familiar e o plano de sucessão podem nos ajudar a compreender o grau de êxito dos processos de sucessão.

Identificar as variáveis que exercem influência no êxito sucessório de empresas do agronegócio familiares pequenas e médias, e entender como elas se comportam, pode ser importante para os proprietários-gestores e suas famílias, bem como para os formuladores de políticas, pois disso pode depender a sobrevivência do negócio. Isso se deve ao fato de que, se o processo sucessório se enfraquece, ou destrói a harmonia familiar, ele também enfraquece ou destrói a confiança entre os membros da família e o engajamento emocional com a organização, requisitos fundamentais para a prosperidade e, a longo prazo, para a sobrevivência das PMEs familiares (Memili, Zellweger, \& Fang, 2013) e a manutenção de milhões de empregos.

Este estudo concentra-se na análise de processos sucessórios exitosos, com base em uma amostra de 230 CEOs de empresas do agronegócio familiares pequenas e médias brasileiras. Até onde sabemos, esta é a primeira pesquisa que utiliza a harmonia familiar e medidas de natureza econômica para explicar os processos sucessórios exitosos de empresas do agronegócio familiares pequenas e médias. Com este trabalho, buscamos contribuir de várias formas para a literatura existente sobre a sucessão exitosa de empresas do agronegócio familiares pequenas e médias. Por um lado, expandimos o conhecimento sobre sucessão exitosa, por meio da investigação dos diferentes fatores que formam este construto. Por outro, este estudo estende a linha de pesquisa, e propõe um modelo que utiliza equações estruturais e um desenho de distanciamento temporal com cinco pontos de coleta de dados, proporcionando, assim, uma melhor compreensão dos processos sucessórios em empresas do agronegócio familiares pequenas e médias. Com base na literatura anterior, também propomos e validamos instrumentos para a medição dos construtos de nosso modelo hipotético.

\section{REFERENCIAL TEÓRICO E HIPÓTESES}

\section{O processo sucessório exitoso}

De acordo com Santos, Ayala-Calvo, e Rodríguez (2019), há três características a se levar em conta na identificação de uma PME de gestão familiar: o envolvimento da família na propriedade e no controle; o envolvimento 
da família na gestão; e o desejo de que o negócio seja passado para a próxima geração. Os contratos relacionais nessas organizações são geralmente baseados em emoções e sentimentos, o que significa que as expectativas mútuas dos diferentes agentes - membros da família ou não - prevalecem sobre as relações contratuais puramente econômicas. Pareceria ilógico, nesse contexto, que os proprietários de uma PME familiar tivessem receio de que o processo sucessório pudesse destruir a harmonia familiar construída ao longo dos anos. Para PMEs familiares, proteger sua identidade, sua reputação e sua forma de fazer negócios, e evitar a interrupção da dinastia familiar são um ativo digno de proteção acima e além de quaisquer razões puramente econômicas ou financeiras. Assim, o ponto de vista da preservação da harmonia familiar é uma perspectiva adequada para explicar a sucessão exitosa do CEO em empresas do agronegócio familiares pequenas e medias.

Não há consenso em relação ao que constitui uma sucessão exitosa, e os estudiosos discordam sobre como medi-la. De acordo com Minichilli et al. (2014), medimos o êxito da sucessão por meio de um construto que incorpore medidas tanto de ordem econômica (crescimento) quanto de ordem não econômica (harmonia familiar). Esta última representa a afinidade dos membros da família com os princípios e valores da empresa, o espírito de ajuda mútua e consciência do bem-estar dos outros membros, o que mostra o nível de organização e união entre os membros da família. Em empresas familiares, a harmonia familiar baseia-se na confiança mútua, construída por meio do convívio saudável entre as pessoas, da história do negócio familiar, de momentos compartilhados e do sentimento de comunidade entre seus membros (Memili et al., 2013). Falkiner, Steen, Hicks, e Keogh (2017) concluíram que a deterioração ou destruição da harmonia familiar durante o processo sucessório poderia, por um lado, diminuir a satisfação dos membros da família com o processo, e, por outro, colocar a sobrevivência da empresa em risco.

Na maioria dos trabalhos anteriores, o êxito de PMEs tem sido medido por sua lucratividade, taxa de crescimento ou desempenho no mercado acionário. Nos últimos anos, no entanto, a variável mais amplamente utilizada tem sido o crescimento, frequentemente visto como resultado da orientação empreendedora do proprietário-gestor (Shan, Song, \& Ju, 2016). Portanto, utilizamos o crescimento como um componente econômico para explicar a sucessão exitosa do CEO em PMEs de gestão familiar.

\section{O entorno e o êxito do plano de sucessão}

0 “compromisso afetivo" do sucessor é um fator-chave no êxito do processo sucessório, na manutenção da harmonia familiar e na garantia do desenvolvimento e sobrevivência da empresa (Cabrera-Suárez \& Martín-Santana, 2010). Sucessores comprometidos assumem o papel de liderança na esperança de contribuir para alcançar os objetivos dos subsistemas envolvidos na empresa familiar (isto é, a empresa e a família), e realizam mais esforços do que seria seu dever em termos estritos. A intensidade da identificação e envolvimento do novo líder com os objetivos da família e da empresa dependerão, em grande medida, do entorno familiar, do entorno organizacional e do entorno econômico ao redor da família e da empresa (Gedajlovic, Carney, Chrisman, \& Kellermanns, 2012); em outras palavras, o êxito do processo de sucessão é condicionado pelo processo de socialização do sucessor, um processo de longo prazo que pode explicar o desejo de potenciais novos CEOs de assumir a empresa da família, e as atitudes que esse desafio implica (Fischer \& Burton, 2014).

\section{Entorno familiar}

O entorno familiar e as relações entre o sucessor e os membros da família são fundamentais para uma sucessão exitosa (Breitenbach \& Corazza, 2017). Quando a comunicação entre os membros da família é aberta e sincera, há mecanis- 
mos para evitar mal-entendidos, e os conflitos são administrados de forma aberta e construtiva. Os membros da nova geração também adquirem um melhor entendimento das vantagens de pertencer à empresa, da importância de preservar a harmonia da família, e do sentimento de sacrifício pessoal necessário para alcançar a prosperidade da empresa da família no longo prazo (Falkiner et al., 2017). Isso, por sua vez, pode influenciar o grau de compromisso do sucessor com a empresa da família e seu interesse em administrá-la. A razão para tanto é que o entorno familiar contribui para o processo de aprendizado do sucessor no que se refere a utilizar a rede social da família, tornar-se mais autossuficiente, aproveitar oportunidades de negócios, e entender e aceitar seu papel etc. Um entorno familiar adequado também estimula a socialização das novas gerações, bem como a transmissão e o entendimento da cultura familiar, definida como sistema de valores compartilhados. Estimula também o sucessor a querer ficar na empresa. Foguesatto et al. (2020) mostraram que, quando os pais transmitem seu amor pelo negócio familiar aos filhos e os motivam a ficar nele, as chances de o herdeiro querer assumir a empresa aumentam significativamente.

Com base nos argumentos acima, formulamos a hipótese de que (Figura 1):

H1: Um entorno familiar adequado exerce uma influência positiva sobre o êxito do processo de sucessão.

\section{Entorno organizacional}

Até o momento, a literatura tem sugerido que a sucessão exitosa pode depender mais do compromisso do sucessor do que de suas habilidades técnicas (Long \& Chrisman, 2014). Isso significa que um grande fator para a sucessão exitosa é quão intimamente o sucessor se identifica com a empresa da família, quão envolvido ele está nela, quão firmemente ele acredita nela e quão elevadas são suas expectativas em relação aos objetivos da empresa. Alguém que pense que suas aspirações profissionais e necessidade de realização podem ser satisfeitas no contexto da empresa familiar se sentirá mais comprometido com ela, e demonstrará um desejo de administrá-la (Fischer \& Burton, 2014).

Um entorno organizacional ótimo estimula o processo de socialização organizacional para que o sucessor possa adquirir todas as atitudes, padrões comportamentais e know-how de que necessitará para trabalhar na empresa. 0 compromisso de um sucessor com a empresa, no entanto, depende menos de seu conhecimento das rotinas, e de como prever e lidar com as respostas dos outros membros da empresa, do que de quão bem o entorno organizacional atrai o sucessor para querer liderar a empresa. Organizações que possuem objetivos claros e procedimentos de avaliação e reconhecimento amplamente aceitos, onde os valores da família foram integrados à gestão, onde há um espírito de trabalho em equipe, e os conflitos são administrados por meio de estratégias do tipo ganha-ganha, são mais atraentes para CEOs do que organizações cujos objetivos não são claros, cujo sistema de remuneração e benefícios é subjetivo, cujo ambiente de trabalho é hostil etc. (Ayala-Calvo et al., 2019). Como mostraram Morais et al. (2017) ou Pessotto et al. (2019), o desejo de potenciais sucessores de ficar no negócio familiar está relacionado ao processo de aprendizado que lhes permita conhecer e amar o ambiente do negócio, e descobrir como gerenciá-lo e administrá-lo.

Com base nos argumentos acima, formulamos a hipótese de que (Figura 1):

H2: Um entorno organizacional adequado exerce uma influência positiva sobre o êxito do processo de sucessão.

\section{Entorno econômico}

O entorno econômico, ou as condições externas, refere-se tanto às variáveis macroeconômicas quanto às regras e regulações (tributação, acesso facilitado a fontes de financiamento, políticas que apoiam o investimento etc.) subjacentes ao desenvolvimento da empresa. 
A empresa é um sistema aberto que influencia e é influenciada pelo que acontece nos cenários macroeconômicos com os quais ela interage. Suas estratégias são intimamente influenciadas pelo comportamento do mercado e das políticas econômicas do país. Um clima econômico favorável a empresas do agronegócio familiares pequenas e médias é aquele em que há crescente demanda interna e externa pelo produto, as políticas governamentais apoiam o desenvolvimento das atividades da empresa do agronegócio familiar, há políticas implementadas para apoiar a mecanização e a inovação, bem como acesso disponível à obtenção de recursos econômicos. Um clima assim traz novas oportunidades ou desafios que podem estimular mudanças positivas nas estratégias da empresa do agronegócio familiar, e, portanto, aumentam o desejo do sucessor de permanecer na empresa da família.

A relação esperada entre as características do ambiente econômico e os desejos do sucessor está ligada à ideia de que a percepção de um clima econômico desfavorável pode prejudicar o crescimento de empresas do agronegócio familiares pequenas e médias, e até mesmo ameaçar sua sobrevivência (Falkiner et al., 2017). Alternativamente, quando o entorno econômico é visto como favorável, o crescimento da empresa é estimulado, e o sucessor fica mais disposto a se comprometer a chefiar o agronegócio familiar, buscando equilibrar a preservação da harmonia familiar e os objetivos econômicos do negócio (May et al., 2019). No caso do Brasil, Matte e Machado (2017), Pessotto et al. (2019) e Foguesatto et al. (2020) têm sugerido que um entorno econômico favorável, que cria nos sucessores expectativas de obter renda econômica suficiente, pode ser uma variável-chave para explicar seu desejo de se tornar líderes do agronegócio familiar.

Com base nos argumentos acima, formulamos a hipótese de que (Fig. 1):

H3: Um entorno econômico adequado exerce uma influência positiva sobre o êxito do processo de sucessão.

\section{O plano de sucessão e o êxito do processo de sucessão}

O plano de sucessão pode ser definido como um conjunto de princípios, ações e etapas envolvidas quando um líder assume a posição de outro. Muitos pesquisadores têm mostrado que o plano de sucessão é o elemento-chave para garantir a continuidade e a prosperidade da empresa familiar (Alayo, Jainaga, Maseda, \& Arzubiaga, 2016). O plano de sucessão contribui para o êxito do processo de várias formas. Por um lado, permite que potenciais candidatos saibam quais os passos e os mecanismos decisórios para a escolha do novo líder, e, por outro, ajuda a preparar a organização para uma sucessão exitosa (Oliveira \& Bernardon, 2008). Os planos de sucessão também ajudam a aumentar a cooperação entre os membros da família e os membros da empresa, e contribuem para aumentar a satisfação de ambos com o processo. Tais planos também constituem um processo de socialização que permite aos novos líderes adquirir mais compreensão das normas da harmonia familiar e aprender a preservá-las.

Embora muito poucos agronegócios familiares já tenham elaborado um plano de sucessão de longo prazo, Cavicchioli, Bertoni, Tesser e Frisio (2015), Conway, McDonagh, Farrell e Kinsella (2016), Falkiner et al. (2017), Quadros, Stropasolas e Rebollar (2013), Pessotto et al. (2019) e outros têm argumentado que o plano de sucessão é fundamental para assegurar a transmissão intergeracional.

Com base nos argumentos acima, formulamos a hipótese de que (Figura 1):

H4: Um plano de sucessão exerce uma influência positiva sobre o êxito do processo de sucessão. 


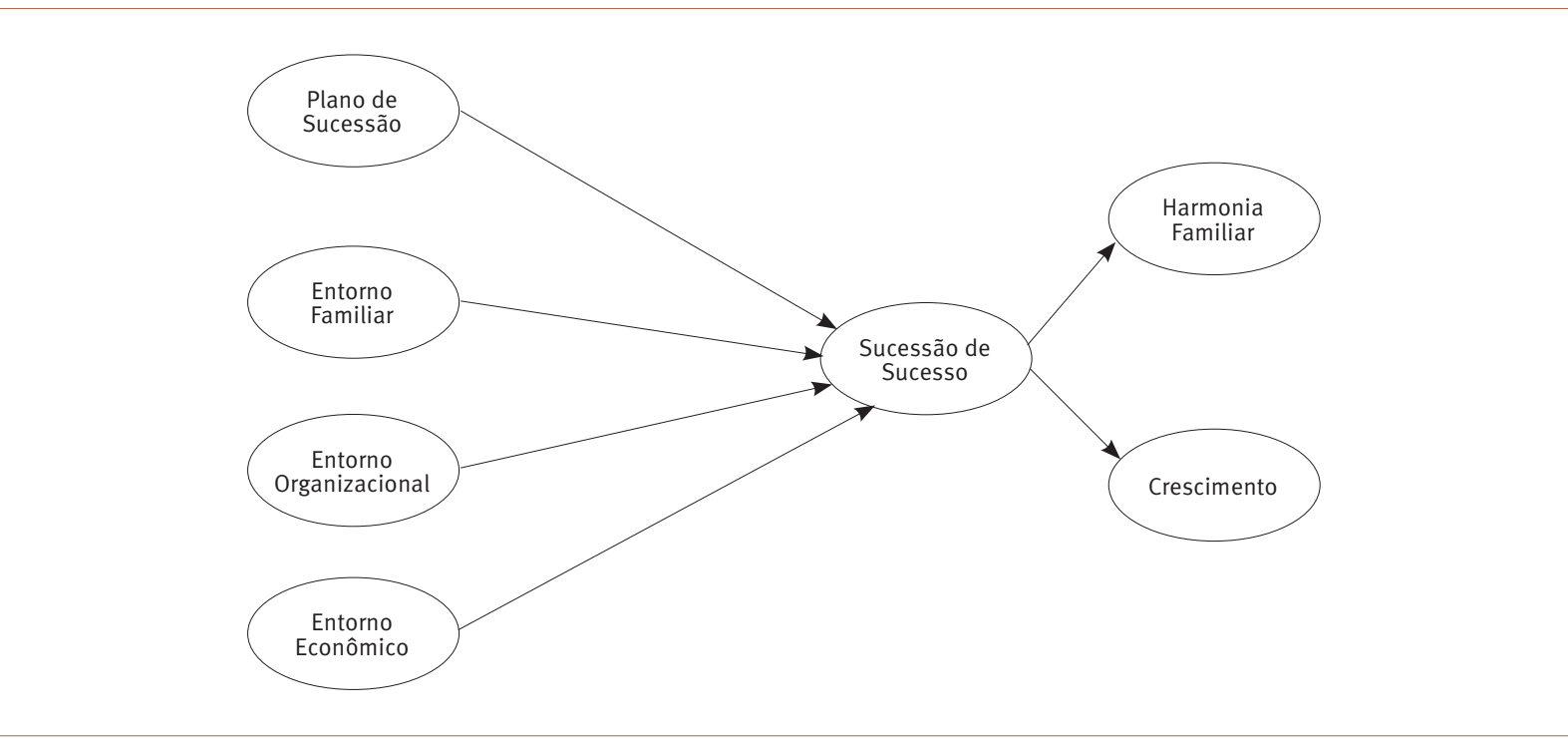

\section{METODOLOGIA}

\section{Amostra e coleta de dados}

A amostra consiste em 230 proprietários-CEOs de PMEs que operam no setor do agronegócio e são localizadas no estado do Paraná (Brasil). Há três razões principais para escolher essas empresas: a) a importância do setor do agronegócio no Brasil; b) a importância do setor do agronegócio no estado do Paraná, e c) a facilidade de acesso à amostra.

Em 2018, empresas familiares do setor do agronegócio geraram mais de $21,1 \%$ do total do PIB brasileiro (Confederação Nacional de Agricultura [CNA], 2019). 0 agronegócio é hoje a força-motriz da economia brasileira. Em 2019, o setor gerou $\$ 89.334$ milhões em exportações, um valor que representa quase $40 \%$ do total de exportações do país. O Paraná ocupa a terceira posição em termos do valor de seu produto bruto ( $\$ 18.223$ milhões), atrás do Mato Grosso (\$18.301 milhões) e de São Paulo (\$21.586 milhões) (Ministério do Desenvolvimento, Indústria e Comércio Exterior [MDIC], 2019).

Para formar nosso grupo amostral, utilizamos o banco de dados do Instituto Brasileiro de Planejamento e Tributação, que em 2015 continha um total de 2.855 empresas privadas ativas fundadas antes de 31 de dezembro de 1994. A razão para a escolha dessa data é a ideia de que a transmissão de empresas familiares geralmente ocorre, no mínimo, 20 anos após sua fundação.

A fim de identificar as empresas familiares e obter uma amostra adequadamente satisfatória, firmamos um acordo de colaboração com a Federação das Associações Comerciais e Empresariais do Estado do Paraná (FACIAP). Como resultado do acordo, foi analisado que dentre as 2.855 empresas identificadas 2.013 preenchiam os requisitos para serem consideradas como PMEs: a) mais de 50\% das ações são de propriedade do fundador ou de membros de sua família; b) pelo menos um membro da família tem o poder de estabelecer as linhas estratégicas da empresa. Finalmente, identificamos 360 empresas que haviam passado por processo de sucessão entre 10 de janeiro de 2014 e 31 de dezembro de 2015. Definimos pequenas empresas como sendo aquelas 
cujas vendas ficaram entre $\$ 67.924$ e $\$ 905.660$, e empresas médias como sendo aquelas cujas vendas ficaram entre $\$ 905.660$,00 e \$56.603.773 (Banco Nacional de Desenvolvimento Econômico e Social [BNDES], 2019). Uma vez identificadas as nossas empresas-alvo, a FACIAP auxiliou nos contatos com as empresas do agronegócio familiares por e-mail, explicou o objetivo de nossa pesquisa e pediu que participassem e colaborassem com nossa coleta de dados. Em janeiro de 2016 ( $\mathrm{T}_{1}$ ), coletamos dados sobre o entorno econômico; em fevereiro de 2016 (T2), dados sobre o entorno familiar; em março de 2016 (T3), dados sobre o entorno organizacional; e em Abril de 2016 (T4), dados sobre os planos de sucessão. Seis entrevistadores, cientes do objetivo deste estudo, telefonaram para os 360 potenciais respondentes. Desses potenciais respondentes, 320 concordaram em participar do estudo, e 313 devolveram questionários utilizáveis (97,8\%). Em 2018 (T5), contatamos esses 313 empresários novamente para saber a opinião deles sobre o êxito da sucessão, dos quais 230 completaram corretamente nosso questionário (73\%) em T5. Escolhemos um intervalo de dois anos com base, principalmente, na ideia de que é necessário um período de tempo suficiente (no mínimo, um ano) para que o sucessor se distancie da dinâmica do processo de sucessão e seja capaz de avaliá-lo de maneira mais sincera e objetiva (Ayala-Calvo et al., 2019). Mas mudanças significativas no plano de sucessão ou na família, no contexto organizacional ou econômico podem ocorrer em dois anos, podendo influenciar o êxito do processo de sucessão. Utilizamos um questionário com oito itens (por ex., "O apoio e a ajuda que você recebe do governo mudou nos últimos dois anos?”) para verificar se o contexto ou o plano de sucessão haviam mudado substancialmente entre 2016 e 2018 . Dois dos respondentes indicaram uma resposta positiva a pelo menos um item, e foram excluídos da análise. Utilizando análise de comparação de médias, constatamos que os 230 participantes da amostra final tinham características semelhantes às dos 83 participantes que não haviam participado em 2018. Especificamente, não havia diferenças significativas na idade das empresas, no número de famílias proprietárias, nas características dos entornos organizacional, familiar e econômico, ou nas características do plano de sucessão. Podemos dizer, portanto, que não houve viés de resposta.

As características da amostra podem ser vistas na Tabela 1.

\section{Desenho do instrumento}

O questionário que utilizamos foi desenvolvido em três etapas. Primeiro, revisamos a literatura em busca de escalas que tivessem sido utilizadas anteriormente para medir os principais construtos de nossa pesquisa. Esses estudos anteriores, no entanto, apenas capturavam aspectos relacionados ao plano de sucessão, à motivação do sucessor ou da pessoa sucedida, ou à composição da diretoria. Para capturar os aspectos multidimensionais do nosso modelo mais plenamente, foi necessário desenvolver nossas próprias escalas com base em questionários anteriores, e nossa própria interpretação da literatura. 0 esboço do questionário foi revisado por dois pesquisadores com experiência em sucessão em empresas familiares. Em seguida, elaboramos um pré-teste com a participação de 10 gestores-proprietários. Este pré-teste nos permitiu verificar a consistência interna dos construtos e descobrir se todos os itens eram compreendidos corretamente. Os resultados do pré-teste e de uma análise fatorial preliminar sugeriram que alguns itens podiam ser eliminados (abaixo de 0,5), e outros, reformulados. Com base nos resultados dessa análise, e após calcular o alfa de Cronbach de cada escala, novamente realizamos ajustes nos questionários, chegando à sua versão final. A maioria dos itens adaptados foram desenvolvidos em inglês. O questionário final foi então traduzido para o português. Um procedimento de retrotradução padrão foi utilizado para assegurar que o conteúdo dos itens estava correto. 
ARTIGOS | SUCESSÃO EXITOSA: O CONTEXTO DO ENTORNO E O PLANO DE SUCESSÃO

Guadalupe Manzano García | Juan-Carlos Ayala-Calvo | Alexandre José Schumacher

Tabela 1. Características da amostra $(\mathrm{N}=\mathbf{2 3 0})$

\begin{tabular}{|c|c|}
\hline $\begin{array}{c}\text { Idade da empresa } \\
(\text { Média }=37,55 \text { anos; Desvio padrão }=3,94)\end{array}$ & $\begin{array}{l}\text { Número de agronegócios } \\
\text { familiares }\end{array}$ \\
\hline $29-34$ anos & 50 \\
\hline $35-39$ anos & 107 \\
\hline $40-44$ anos & 61 \\
\hline $45-49$ anos & 11 \\
\hline 50-51 anos & 1 \\
\hline \multicolumn{2}{|l|}{ Número de famílias acionistas da empresa. } \\
\hline 1 & 188 \\
\hline 2 & 36 \\
\hline 3 & 5 \\
\hline 4 & 1 \\
\hline \multicolumn{2}{|l|}{ Geração na empresa } \\
\hline Segunda geração & 203 \\
\hline Terceira geração & 27 \\
\hline \multicolumn{2}{|l|}{$\begin{array}{l}\text { Mudança geracional: anos após a fundação } \\
\text { (Média = 31,61 anos; Desvio padrão = 4,8) }\end{array}$} \\
\hline$<25$ & 14 \\
\hline $25-29$ & 64 \\
\hline $30-34$ & 99 \\
\hline $35-39$ & 44 \\
\hline 40-45 & 9 \\
\hline \multicolumn{2}{|l|}{ Tamanho } \\
\hline Pequena & 83 \\
\hline Média & 147 \\
\hline
\end{tabular}

\section{Variáveis}

As variáveis, os itens utilizados para medi-las e os autores nos quais nossa definição de cada variável foi baseada podem ser vistos no Quadro 1. Os respondentes classificaram seu nível de concordância ou discordância de cada item em uma escala Likert de 5 pontos, onde 1 significa "discordo fortemente", e 5 significa "concordo fortemente". As confiabilidades do a de Cronbach para todas as escalas foi maior do que 0,70 (seu valor crítico). 


\section{Quadro 1. Descrição das variáveis utilizadas na análise}

\begin{tabular}{|c|c|c|}
\hline Variáveis & Descrição & Fonte \\
\hline $\begin{array}{l}\text { Dados } \\
\text { sociodemográficos }\end{array}$ & $\begin{array}{l}\text { 1. Indique o ano em que sua empresa iniciou as atividades. } \\
\text { 2. Indique o número atual de famílias acionistas na empresa. } \\
\text { 3. Indique quais gerações estão trabalhando atualmente em sua empresa: } \\
\text { O fundador e seus filhos } \\
\text { Só os filhos do fundador } \\
\text { Os netos do fundador e seus pais } \\
\text { Só os netos do fundador } \\
\text { Os descendentes dos netos do fundador } \\
\text { 4. Indique o ano em que a substituição geracional ocorreu. }\end{array}$ & \\
\hline Plano de sucessão & $\begin{array}{l}\text { O plano de sucessão: } \\
\text { 1. Considera que o sucessor e o sucedido trabalharão juntos por algum tempo. } \\
\text { 2. Considera os conhecimentos e as habilidades que devem ser avaliados em todos os } \\
\text { possíveis candidatos da família a CEO da empresa. } \\
\text { 3. Inclui os valores familiares e empresariais que o possível novo CEO da empresa deve } \\
\text { possuir. } \\
\text { 4. Detalha como será gerida a incorporação de um possível CEO no processo de tomada } \\
\text { de decisões da empresa. }\end{array}$ & $\begin{array}{l}\text { Motwani et } \\
\text { al. (2006) and } \\
\text { Venter et al., } \\
(2005) \text {. }\end{array}$ \\
\hline Entorno familiar & $\begin{array}{l}\text { Em minha família: } \\
\text { 1. Quando surge um conflito, lidamos com ele abertamente. } \\
\text { 2. A comunicação ativa entre os membros é promovida. } \\
\text { 3. Cada membro é valorizado por suas capacidades e habilidades. } \\
\text { 4. Antes de tomar qualquer decisão que afete a família ou a empresa, todas as } \\
\text { possibilidades são avaliadas. } \\
\text { 5. O treinamento dos integrantes da empresa é promovido considerando suas } \\
\text { preferências. } \\
\text { 6. Incentivamos os membros da nova geração a trabalhar ao lado dos membros da } \\
\text { geração atual. } \\
\text { 7. Os valores de transmissão que tornaram nossa empresa mais forte são promovidos. }\end{array}$ & \multirow{3}{*}{$\begin{array}{l}\text { Todos os } \\
\text { itens foram } \\
\text { desenvolvidos } \\
\text { pelos autores } \\
\text { ou adaptados } \\
\text { dos estudos de } \\
\text { Cabrera-Suárez } \\
\text { e Martín- } \\
\text { Santana, (2010) } \\
\text { and Duarte e } \\
\text { Oliveira, (2010). }\end{array}$} \\
\hline $\begin{array}{l}\text { Entorno } \\
\text { organizacional }\end{array}$ & $\begin{array}{l}\text { Em nossa empresa: } \\
\text { 1. As funções de cada cargo são claras. } \\
\text { 2. Os valores da família são levados em consideração no processo de tomada de } \\
\text { decisões. } \\
\text { 3. Os objetivos da empresa são claros e conhecidos por todos os funcionários. } \\
\text { 4. A avaliação de desempenho do cargo e os critérios de promoção são conhecidos por } \\
\text { todos os funcionários. } \\
\text { 5. Quando surge algum conflito ou problema, a empresa trabalha muito para encontrar } \\
\text { soluções que, na medida do possível, beneficiem todos os funcionários. } \\
\text { 6. O trabalho em equipe é promovido entre todos os funcionários. } \\
\text { 7. A comunicação ascendente e descendente é rápida e oportuna. }\end{array}$ & \\
\hline Entorno econômico & $\begin{array}{l}\text { Sobre nossa fazenda familiar: } \\
\text { 1. As mudanças na política econômica do governo comprometem seu desempenho. } \\
\text { 2. O desempenho da empresa depende muito do acesso ao financiamento e de seu custo. } \\
\text { 3. As políticas governamentais de apoio ao investimento são cruciais para o } \\
\text { desenvolvimento da empresa. } \\
\text { 4. As políticas fiscais do governo têm grande influência em nossa estratégia de } \\
\text { crescimento e desenvolvimento. } \\
\text { 5. O crescimento do PIB nacional influencia o nosso crescimento. }\end{array}$ & \\
\hline Sucessão exitosa & $\begin{array}{l}\text { Harmonia familiar } \\
\text { 1. As pessoas da minha família são muito compatíveis umas com as outras. } \\
\text { 2. A interação diária entre os membros da família é cordial. } \\
\text { 3. Os membros da família apoiam uns aos outros. } \\
\text { 4. Os membros da família agem em harmonia. } \\
\text { Crescimento } \\
\text { 1. } 0 \text { crescimento nas vendas nos dois anos após a sucessão foi: } \\
\text { 2. } 0 \text { crescimento acumulado da empresa nos dois anos seguintes à sucessão, em } \\
\text { comparação com outras empresas do setor, foi: }\end{array}$ & $\begin{array}{l}\text { Kavikondala et } \\
\text { al. (2016). }\end{array}$ \\
\hline
\end{tabular}




\section{Análise de dados}

Utilizamos a modelagem de equações estruturais por mínimos quadrados parciais (PLS-SEM) para testar o modelo de pesquisa proposto. As razões que justificam seu uso neste trabalho são (Chin, 2010): a) a amostra não excede 250 indivíduos; b) nosso modelo adiciona a outros modelos existentes novas variáveis e novas formas de medi-las; c) queremos avaliar em que medida as variáveis independentes são capazes de prever a variável dependente.

Para medir a variável "sucessão exitosa", utilizamos a abordagem de dois passos proposta por Chin (2010). A aceitação ou rejeição das hipóteses incluídas no modelo proposto, como é comum neste tipo de análise, foi determinada utilizando três critérios: o $R^{2}$ do construto dependente, os coeficientes de caminhos padronizados (B) e a relevância preditiva $\left(\mathrm{Q}^{2}\right)$. Para gerar erros padrão, valores-t dos parâmetros e os intervalos de confiança bootstrap de $95 \%$ corrigidos em relação ao viés, utilizamos o método de bootstrapping (5.000 amostras). Se a variação entre os limites inferior e superior de um intervalo para uma dada relação não contivesse zero, interpretamos esta relação como sendo estatisticamente significante. 0 nível de corte do $\mathrm{R}^{2}$ para as variáveis dependentes é de 10\%. O nível de corte para o teste de estatística de $Q^{2}$, obtido por meio de blindfolding, é zero. Utilizamos o software PLS 3.0.

\section{RESULTADOS}

A Tabela 2 mostra as correlações, médias e desvios padrão das principais variáveis do estudo.

\section{Tabela 2. Estatísticas descritivas e correlações}

\begin{tabular}{|c|c|c|c|c|c|c|c|c|}
\hline & \multirow[t]{2}{*}{ Média } & \multirow[t]{2}{*}{ DP } & \multicolumn{6}{|c|}{ Correlações } \\
\hline & & & 1 & 2 & 3 & 4 & 5 & 6 \\
\hline 1 Harmonia Familiar & 12,02 & 3,86 & 0,88 & & & & & \\
\hline 2 Crescimento & 6,34 & 0,64 & $0,32^{\star \star}$ & 0,73 & & & & \\
\hline 3 Entorno Familiar & 24,08 & 6,22 & $0,33^{\star \star}$ & $0,30^{\star *}$ & 0,91 & & & \\
\hline 4 Entorno Organizacional & 21,80 & 6,70 & $0,15^{\star *}$ & $0,16^{\star}$ & $0,39^{\star *}$ & 0,92 & & \\
\hline 5 Entorno Econômico & 17,52 & 3,15 & $0,48^{\star \star}$ & 0,30 & $0,41^{\star *}$ & $0,42^{\star *}$ & 0,85 & \\
\hline 6 Plano de Sucessão & 11,27 & 4,19 & $0,29^{\star \star}$ & $0,28^{\star \star}$ & $0,31^{\star}$ & $0,46^{\star}$ & $0,33^{\star \star}$ & 0,89 \\
\hline
\end{tabular}

Nota: As confiabilidades do a de Cronbach's para as escalas são mostradas na diagonal. ** Significativo em p<o,001, * significativo em p<o,05

\section{Modelo de medição}

A Tabela 3 mostra a confiabilidade individual dos itens, bem como a confiabilidade composta e a validade convergente dos construtos. 
ARTIGOS | SUCESSÃO EXITOSA: O CONTEXTO DO ENTORNO E O PLANO DE SUCESSÃO

Guadalupe Manzano García | Juan-Carlos Ayala-Calvo | Alexandre José Schumacher

Tabela 3. Modelo de medição: cargas, confiabilidade e validade convergente dos construtos

\begin{tabular}{|c|c|c|c|}
\hline Construto/dimensão/indicador & Carga & $\begin{array}{l}\text { Confiabilidade } \\
\text { composta }\end{array}$ & AVE \\
\hline Entorno Familiar (EF) & & 0,93 & 0,65 \\
\hline EF1 & 0,71 & & \\
\hline $\mathrm{EF} 2$ & 0,80 & & \\
\hline $\mathrm{EF}_{3}$ & 0,74 & & \\
\hline $\mathrm{EF}_{4}$ & 0,86 & & \\
\hline $\mathrm{EF}_{5}$ & 0,84 & & \\
\hline EF6 & 0,88 & & \\
\hline EF7 & 0,79 & & \\
\hline Entorno Econômico (EE) & & 0,89 & 0,62 \\
\hline $\mathrm{EE} 1$ & 0,81 & & \\
\hline $\mathrm{EE} 2$ & 0,83 & & \\
\hline EE3 & 0,86 & & \\
\hline $\mathrm{EE} 4$ & 0,71 & & \\
\hline $\mathrm{EE}_{5}$ & 0,71 & & \\
\hline Entorno Organizacional (EO) & & 0,94 & 0,69 \\
\hline $\mathrm{EO} 1$ & 0,81 & & \\
\hline $\mathrm{EO}_{2}$ & 0,75 & & \\
\hline $\mathrm{EO}_{3}$ & 0,86 & & \\
\hline $\mathrm{EO}_{4}$ & 0,88 & & \\
\hline $\mathrm{EO}_{5}$ & 0,85 & & \\
\hline E06 & 0,85 & & \\
\hline $\mathrm{EO} 7$ & 0,82 & & \\
\hline Plano de Sucessão (PS) & & 0,92 & 0,75 \\
\hline PS1 & 0,88 & & \\
\hline PS2 & 0,89 & & \\
\hline PS3 & 0,93 & & \\
\hline PS4 & 0,76 & & \\
\hline Sucessão Exitosa (SE) & & 0,82 & 0,69 \\
\hline Harmonia Familiar (HF) & & 0,89 & 0,67 \\
\hline $\mathrm{HF} 1$ & 0,78 & & \\
\hline $\mathrm{HF} 2$ & 0,76 & & \\
\hline $\mathrm{HF}_{3}$ & 0,82 & & \\
\hline $\mathrm{HF}_{4}$ & 0,81 & & \\
\hline Crescimento (C) & & 0,77 & 0,63 \\
\hline $\mathrm{C}_{1}$ & 0,83 & & \\
\hline $\mathrm{C}_{2}$ & 0,75 & & \\
\hline
\end{tabular}


A confiabilidade individual para todos os itens foi maior do que 0,707, que é considerado um valor mínimo, ou nível de corte. Além disso, todos os construtos tiveram uma confiabilidade composta acima de o,7, que é considerado o nível de corte. Ademais, todos os construtos tiveram uma variância média extraída (AVE) mais elevada do que o valor mínimo considerado (o,5), o que mostra a validade convergente dos construtos. Esses resultados mostram que o modelo de medição é bom.

Finalmente, como mostra a Tabela 4, a raiz quadrada da AVE de um dado construto é maior do que a correlação entre esse construto e o restante dos construtos do modelo. Portanto, pode-se afirmar que os construtos diferem uns dos outros.

Tabela 4. Modelo de medição: validade discriminante

\begin{tabular}{|c|c|c|c|c|c|}
\hline & $\mathrm{EF}$ & $\mathrm{EE}$ & EO & os & SE \\
\hline $\mathrm{FE}$ & $(0,81)$ & & & & \\
\hline $\mathrm{EE}$ & $0,41^{\star \star}$ & $(0,79)$ & & & \\
\hline EO & $0,39^{\star *}$ & $0,42^{\star \star}$ & $(0,83)$ & & \\
\hline OS & $0,31^{*}$ & $0,33^{* *}$ & $0,46^{*}$ & $(0,87)$ & \\
\hline SE & $0,40^{\star \star}$ & $0,33^{\star \star}$ & $0,16^{* *}$ & $0,28^{\star \star}$ & $(0,83)$ \\
\hline
\end{tabular}

Notas: EF (Entorno Familiar), EE (Entorno Econômico), EO (Entorno Organizacional), PS (Plano de Sucessão), SE (Sucessão Exitosa). As raízes quadradas da Variância Média Extraída (AVE) são apresentadas entre parênteses na diagonal. Os elementos fora da diagonal são as relações entre os construtos. * p<0,05; ** $p<0,01$

\section{Modelo estrutural}

A Tabela 5 mostra que todas as quatro relações das hipóteses de nosso modelo eram significativas. $O \mathrm{R}^{2}$ para a variável dependente também era maior do que $10 \%$. E o Q ${ }^{2}$ era maior do que zero.

Tabela 5. Resultados do modelo estrutural

\begin{tabular}{|c|c|c|c|c|}
\hline \multicolumn{3}{|c|}{$\mathrm{R}^{2} \mathrm{SS}=.51 ; \mathrm{Q}^{2} \mathrm{SS}=.14$} & \multicolumn{2}{|c|}{$\begin{array}{l}\text { Intervalos de confiança bootstrap de } 95 \% \\
\text { corrigidos em relação ao viés }\end{array}$} \\
\hline \multirow{2}{*}{ Relações } & \multirow{2}{*}{$\begin{array}{l}\text { Coeficientes de } \\
\text { caminho }\end{array}$} & \multirow{2}{*}{ Valor-p } & Inferior & Superior \\
\hline & & & & \\
\hline $\mathrm{EF} \rightarrow \mathrm{SE}$ & 0,292 & 0,000 & 0,154 & 0,436 \\
\hline $\mathrm{EO} \rightarrow \mathrm{SE}$ & 0,155 & 0,014 & 0,038 & 0,271 \\
\hline $\mathrm{EE} \rightarrow \mathrm{SE}$ & 0,330 & 0,000 & 0,274 & 0,385 \\
\hline $\mathrm{PS} \rightarrow \mathrm{SE}$ & 0,281 & 0,000 & 0,193 & 0,366 \\
\hline
\end{tabular}

Notas: EF (Entorno Familiar), EE (Entorno Econômico), EO (Entorno Organizacional), PS (Plano de Sucessão), SE (Sucessão Exitosa). 


\section{DISCUSSÃO E IMPLICAÇÕES}

Em uma PME, a sucessão do CEO é geralmente um processo crítico, e muitos pesquisadores têm tentado entender os fatores que afetam seu êxito (Foguesatto et al., 2020; May et al., 2019; Pessotto et al., 2019). Em vez de se aprofundar em uma análise de qualquer fator específico, este estudo defende a necessidade de uma visão mais integrativa. Nosso modelo parte da ideia de que a identificação de uma sucessão exitosa deve utilizar tanto fatores econômicos quanto não econômicos. Dado o alto nível de envolvimento da família na empresa, e seu compromisso com ela e com sua riqueza econômica, o processo de sucessão também deve preservar a harmonia familiar. Os resultados demonstram que o construto "sucessão exitosa" (confiabilidade composta =0,82; AVE =0,69) foi corretamente definido utilizando variáveis que reúnem a combinação de motivos e desejos (econômicos e emocionais) que refletem os interesses que os proprietários da empresa do agronegócio familiar esperam proteger. Este resultado apoia Minichilli et al. (2014), que observaram que uma sucessão exitosa significava encontrar um equilíbrio entre a busca por resultados econômicos e não econômicos.

Nossa pesquisa mostrou que tanto o plano de sucessão quanto os entornos familiar e emocional são formas válidas para socializar e envolver um novo CEO em um agronegócio familiar. Eles são eficazes em assegurar que o candidato escolhido compreenda e concorde com o tempo e esforço necessários para alcançar um equilíbrio entre os objetivos econômicos (crescimento) e não econômicos (harmonia familiar). Esses resultados apoiam os resultados encontrados na literatura anterior, que sugerem que o contexto da sucessão exerce um efeito significativo sobre a percepção do êxito da sucessão (Breitenbach \& Corazza, 2017; Foguesatto et al., 2020; Morais et al., 2017). Nossos achados também apoiam os estudos que apontaram as dinâmicas de comunicação, colaboração e planejamento como sendo fatores fundamentais para o êxito da sucessão (Pessotto et al., 2019; Quadros et al., 2013).

O entorno econômico é a variável que exerce mais influência sobre o êxito da sucessão, e também aquele sobre o qual os proprietários das empresas têm menos controle. Isto sugere que, em entornos econômicos desfavoráveis, é mais difícil encontrar candidatos dispostos a se comprometer com uma empresa cujo futuro é incerto (Pessotto et al., 2019). Entretanto, devemos levar em consideração que as empresas familiares podem utilizar outras variáveis do modelo, as variáveis sobre as quais elas têm mais controle, para influenciar a percepção e interpretação dos sucessores acerca do entorno econômico. Assim, os processos de socialização que ocorrem no entorno familiar e/ou organizacional podem ser utilizados para ajudar os novos líderes a ver oportunidade onde outros veem apenas ameaças, para conviver e lidar com a incerteza, para se vincular emocionalmente com o agronegócio da família, ou para utilizar as redes no entorno para beneficiar a empresa ou a família (Ayala \& Manzano, 2014). Segundo Fischer e Burton (2014), quanto mais o processo de socialização aumenta a conexão entre o sucessor e o agronegócio da família, menos influência o entorno econômico exercerá sobre as decisões do sucessor sobre tornar-se ou não o novo CEO. Deste ponto de vista, para que o agronegócio familiar seja transferido com êxito entre as gerações, a ênfase deve ser colocada em nutrir a paixão, o orgulho e a conexão do possível sucessor com a área territorial. Esses sentimentos, que são transmitidos durante o processo de socialização, podem ser críticos para a sobrevivência dos agronegócios familiares e, portanto, para a manutenção da população nas áreas rurais (Foguesatto et al., 2020; Pessotto et al., 2019).

A considerável influência do entorno econômico sobre a sucessão exitosa em PMEs do agronegócio familiares $(\beta=0,33)$ e, portanto, sobre sua sobrevivência, sugere que há implicações significativas para os formuladores de políticas. Estes formuladores de políticas são os responsáveis por implementar políticas que apoiem direta- 
mente as PMEs; políticas que as ajudem a competir nos mercados interno e externo, a melhorar sua P\&D, e a não ter de superar obstáculos demais para obter recursos financeiros a um custo viável. Além das políticas voltadas à melhoria dos resultados econômicos dos agronegócios familiares, outras políticas podem também ser implementadas para estimular a sucessão, incluindo: a promoção de planos de aposentadoria antecipada que garantam segurança econômica para os que se aposentam, planos de capacitação e apoio para desenvolver as habilidades dos sucessores, assistência na elaboração de planos de sucessão etc. Os formuladores de política também podem implementar políticas para evitar quebras abruptas nos ciclos de socialização dos sucessores nas fases iniciais de suas vidas. 0 aumento do número de anos de educação compulsória, a distância das escolas, uma preocupação crescente com a saúde das crianças etc. tornam cada vez mais difícil manter um contato prolongado entre a família, a criança e o próprio agronegócio familiar. Para a sucessão do CEO ser exitosa, ela deve ser planejada, e o desenvolvimento dos contextos familiar e organizacional que promovem a confiança, o apoio mútuo, os valores compartilhados, a paixão negócio da família, o orgulho do pertencimento, a resolução de conflitos, e o reconhecimento e respeito pelas regras devem ser estimulados. Isto pode ser alcançado ensinando potenciais sucessores a praticar a comunicação ativa; incentivando sua participação progressiva, dependendo de sua idade e habilidades adquiridas, no trabalho do agronegócio familiar e em suas instâncias decisórias; ou ensinando-lhes os valores da cultura familiar, o orgulho envolvido em administrar um agronegócio familiar, e as boas práticas sobre as quais a reputação do agronegócio familiar foi construída.

Como todas as pesquisas, nosso estudo também tem suas limitações. Primeiramente, a amostra baseia-se em empresas do agronegócio familiares no Brasil, um país em desenvolvimento. Pesquisas futuras poderiam verificar se nossos achados também valem para contextos econômicos e sociais diferentes, como em amostras de outros países e de outros setores. Em segundo lugar, todos os dados analisados foram fornecidos pelo CEO atual. Para um entendimento mais aprofundado do processo de sucessão, valeria a pena obter diferentes pontos de vista do sucessor, do líder que deixa a empresa, e de outros membros da família. Pesquisas futuras deveriam trazer mecanismos para levar este fato em consideração. Em terceiro lugar, a variável do entorno organizacional não levou em consideração as estruturas de governança do agronegócio familiar. Em pesquisas futuras, seria interessante ver ser as relações encontradas em nossa pesquisa se mantêm, independentemente das estruturas de governança do agronegócio familiar.

Apesar dessas limitações, nosso trabalho contribui para a literatura sobre sucessão em PMEs de várias formas. Primeiramente, os estudos anteriores levaram em consideração o contexto organizacional (Minichilli et al., 2014) ou o contexto familiar (Cabrera-Suárez \& Martín-Santana, 2010), mas não encontramos nenhum que levasse em conta o entorno econômico. Tampouco encontramos pesquisa que tivesse integrado o efeito de todos os três tipos de entorno em um único modelo. Em segundo lugar, embora alguns autores tenham sugerido (Delgado-García \& Fuente-Sabaté, 2009), até onde sabemos, este é o primeiro estudo a incluir fatores econômicos e não econômicos para medir o êxito do processo de sucessão. Terceiro, para a maioria das variáveis utilizadas em nossa pesquisa, as escalas de medição ou não existiam ou eram incompletas. Todas as escalas desenvolvidas para este estudo demonstraram possuir elevada confiabilidade (a de Cronbach > 0,73, confiabilidade composta $>$, 77). Quando comparado com desenhos transversais, nosso desenho de estudo também permite que as hipóteses do modelo proposto sejam testadas de um modo mais rigoroso. Medir os entornos econômico, familiar e organizacional e o plano de sucessão em diferentes momentos no tempo permite que o impacto potencial da variância do método comum seja minimizado. Isto porque o desenho de distanciamento temporal cria uma separação temporal, contextual e psicológica (Podsakoff, MacKenzie, Lee, \& Podsakoff, 2003). Finalmente, esta pesquisa aumentou o conhecimento acerca dos fatores que afetam a sucessão exitosa em agronegócios familiares pequenos e médios no Brasil, a nona maior economia do mundo. 


\section{REFERÊNCIAS}

Alayo, M., Jainaga, T., Maseda, A., \& Arzubiaga, U. (2016). Critical factors for successful succession of family firms. European Journal of Economics, Finance and Administrative Sciences, 85 , 90-103. Recuperado de http://www.europeanjournalofeconomicsfinanceandadministrativesciences.com

Ayala, J. C., \& Manzano, G. (2014). The resilience of the entrepreneur: Influence on the success of the business - A longitudinal analysis. Journal of Economic Psychology, 42, 126-135. doi: 10.1016/j.joep.2014.02.004

Ayala-Calvo, J. C. A., Manzano-García, G., \& Schumacher, A. (2019). Êxito na sucessào de empresas familiares? Factores de influência (Success in the succession of family businesses. Influencing factors). XXIX Jornadas Hispano-Lusas de Gestión Científica - Emprendimiento, Estrategia y Conocimiento (pp. 88-89). Osuna: Universidad de Sevilla.

Banco Nacional de Desenvolvimento Econômico e Social. (2019). Micro, pequenas e médias empresas. Recuperado de https:// www.bndes.gov.br/wps/portal/site/home/onde-atuamos/ micro-pequenas-medias-empresas

Breitenbach, R., \& Corazza, G. (2017). Perspectiva de permanência no campo: Estudo dos jovens rurais de Alto Alegre, Rio Grande do Sul/Brasil. Espacios, 38(29), 9-20.

Cabrera-Suárez, M. K., \& Martín-Santana, J. (2010). La influencia de las relaciones intergeneracionales en la formación y el compromiso del sucesor: Efectos sobre el proceso de sucesión en la empresa familiar (The influence of intergenerational relationships on the formation and commitment of the successor). Revista Europea de Direccion y Economia de La Empresa, 19(2), 111-128.

Cavicchioli, D., Bertoni, D., Tesser, F., \& Frisio, D. (2015). What factors encourage intra-family farm succession in mountain areas? Evidence from an alpine aalley in Italy. Mountain Research and Development, 35(2), 152-160. doi: 10.1659/ MRD-JOURNAL-D-14-00107.1

Chin, W. (2010). How to write up and report PLS analyses. In W. H. Esposito, V. Vinzi, W. Chin, \& J. Henseler (Eds.), Handbook of partial least squares. (pp. 655-690). London: Springer. /doi: 10.1007/978-3-540-32827-8_29Springer.

Confederação Nacional de Agricultura. (2019). Panorama do agro. Recuperado de https://www.cnabrasil.org.br/cna/ panorama-do-agro

Conway, S. F., McDonagh, J., Farrell, M., \& Kinsella, A. (2016). Cease agricultural activity forever? Underestimating the importance of symbolic capital. Journal of Rural Studies, 44, 164-176. doi:10.1016/j.jrurstud.2016.01.016

Delgado-García, J., \& Fuente-Sabaté, J. (2009). How do CEO emotions matter? Impact of CEO affective traits on strategic and performance conformity in the Spanish banking industry. Strategic Management Journal, 31(5), 562-574. doi: 10.1002/smj.817
Duarte, F., \& Oliveira, L. (2010). Análise de maturidade em processos sucessórios de empresas familiares. Revista de Gestão, 17(2), 135-150. doi: 10.5700/rege391

Falkiner, O., Steen, A., Hicks, J., \& Keogh, D. (2017). Current practices in Australian Farm succession planning: Surveying the issues. Financial Planning Research Journal, 1(1), 59-74.

Fischer, H., \& Burton, R. J. F. (2014). Understanding farm succession as socially constructed endogenous cycles. Sociologia Ruralis, 54(4), 417-438. doi: 10.1111/soru.12055

Foguesatto, C. R., Mores, G. de V., Kruger, S. D., \& Costa, C. (2020). Will I have a potential successor? Factors influencing family farming succession in Brazil. Land Use Policy, 97, 2020, 104643. doi: 10.1016/j.landusepol.2020.104643

Garner, E., \& Campos, A. P. O. (2014). Identifying the "family farm": An informal discussion of the concepts and definitions. FAO. Recuperado de http://www.fao.org/3/a-i4306e.pdf

Gedajlovic, E., Carney, M., Chrisman, J. J., \& Kellermanns, F. W. (2012). The adolescence of family firm research: Taking stock and planning for the future. Journal of Management, 38(4), 1010-1037. doi: 10.1177/0149206311429990

Inter American Development Bank, United Nations, \& Organization of American States. (2011). Innovating, gaining market share and fostering social inclusion: Success stories in SME development. Recuperado de https://publications. iadb.org/en/innovating-gaining-market-share-and-fosteringsocial-inclusion-success-stories-sme-development

Kavikondala, S., Stewart, S. M., Ni, M. Y., Chan, B. H. Y., Lee, P. H., Li, K.K., ... Leung, G. M. (2016). Structure and validity of family harmony scale: An instrument for measuring harmony. Psychological Assessment, 28(3), 307-318. doi:10.1037/pas0000131

Long, R. G., \& Chrisman, J. J. (2014). Management succession in family business. In M. N. \& P. S. L. Melin (Eds.), Sage handbook of family business (pp. 249-268). Thousand Oaks: Sage Publications, Inc.

Matte, A., \& Machado, J. A. D. (2017). Tomada de decisão e a sucessão na agricultura familiar no sul do Brasil. Revista de Estudos Sociais, 18(37), 130. doi:10.19093/res.v18i37.3981

May, D., Arancibia, S., Behrendt, K., \& Adams, J. (2019). Preventing young farmers from leaving the farm: Investigating the effectiveness of the young farmer payment using a behavioural approach. Land Use Policy, 82, 317-327. doi: 10.1016/j.landusepol.2018.12.019

Memili, E., Zellweger, T. M., \& Fang, H. (2013). The determinants of family owner-managers' affective organizational commitment. Family Relations, 62(3), 443-456. doi: 10.1111/fare.12015

Minichilli, A., Nordqvist, M., Corbetta, G., \& Amore, M. (2014). CEO Succession mechanisms, organizational context, and performance: A Socio-emotional wealth perspective on family-controlled firms. Journal of Management Studies, 51(7), 1153-1179. doi: 10.1111/joms.12095 
Ministério do Desenvolvimento, Indústria e Comércio Exterior. (2019). Balanza comercial brasilena: Acumulado del ano. Recuperado de http://www.mdic.gov.br/index.php/ comercio-exterior/estatisticas-de-comercio-exterior/balancacomercial-brasileira-acumulado-do-ano

Morais, M., Borges, J., \& Erlaine, B. (2017). Using the reasoned action approach to understand Brazilian successors' intention to take over the farm. Land Use Policy, 71, 445-452. doi: 10.1016/j.landusepol.2017.11.002

Motwani, J., Levenburg, N.M., Schwarz, T.V., \& Blankson, B. (2006). Succession planning in SMEs: an empirical analysis. International Small Business Journal 24(5), 471-495.

Nikolić, N., Jovanović, I., Nikolić, Đ., Mihajlović, I., \& Schulte, P. (2018). Investigation of the factors influencing sme failure as a function of its prevention and fast recovery after failure. Entrepreneurship Research Journal, 9(3), 1-21. doi: 10.1515/erj-2017-0030

Oliveira, L., \& Bernardon, R. (2008). Instrumento para avaliação de diretrizes estratégicas de sucessão empresarial (A tool for evaluating strategig guidelines for business succesion). Gestão \& Planejamento, 9(2), 141-158.

Organisation for Economic Co-operation and Development. (2018). Financing SMES and E entrepreneurs 2018. OECD. Recuperado de https://doi.org/https://doi.org/10.1787/fin_ sme_ent-2018-16-en

Pessotto, A. P., Costa, C., Schwinghamer, T., Colle, G., \& Corte, V. F. D. (2019, June). Factors influencing intergenerational succession in family farm businesses in Brazil. Land Use Policy, 87, 104045. https://doi.org/10.1016/j. landusepol.2019.104045
Podsakoff, P. M., MacKenzie, S. B., Lee, J. Y., \& Podsakoff, N. P. (2003). Common Method biases in behavioral research: A critical review of the literature and recommended remedies. Journal of Applied Psychology, 88(5), 879-903. doi: 10.1037/0021-9010.88.5.879

Quadros, C. De, Stropasolas, V. L., \& Rebollar, P. B. M. (2013). A participação dos jovens nas agroindústrias familiares do litoral sul catarinense e as implicações no processo sucessório. Revista Pedagógica, 13(26), 125. doi: 10.22196/ rp.v13i26.1268

Santos, E., Ayala-Calvo, J., \& Rodríguez, E. (2019). Clasificación de las empresas familiares en base a sus valores. Cuadernos de Economía, 42, 70-80. doi: 10.32826/cude.v42i118.74

Schumacher, A. (2015). Éxito en la sucesión de empresas familiares: Factores de influencia [Universidad de La Rioja, Logroño, La Rioja, Spain)]. Recuperado de https://dialnet. unirioja.es/servlet/tesis?codigo $=46494$

Shan, P., Song, M., \& Ju, X. (2016). Entrepreneurial orientation and performance: Is innovation speed a missing link? Journal of Business Research, 69(2), 683-690. doi: 10.1016/j. jbusres.2015.08.032

Sharma, P. (2004). An overview of family business studies: Current status and directions for the future. Family Business Review, 17(1), 1-36. doi: 10.1111/j.1741-6248.2004.00001.x

Venter, E., Boshoff, C. \& Maas, G. (2005). The influence of successor-related factors on the succession process in small and medium-sized family businesses. Family Business Review, 18(4), 283-303. https://doi.org/10.1111/j.1741 6248.2005.00049.x

\section{CONTRIBUIÇÕES DOS AUTORES}

Os autores declaram que participaram de todos os estágios do desenvolvimento do manuscrito. Guadalupe Manzano García, Juan-Carlos Ayala-Calvo e Alexandre José Schumacher trabalharam na conceitualização e na abordagem teórico-metodológica. A revisão teórica foi conduzida por Guadalupe Manzano García, Juan-Carlos Ayala-Calvo e Alexandre José Schumacher. A coleta de dados foi coordenada por Guadalupe Manzano García. A análise dos dados incluiu Guadalupe Manzano García, Juan-Carlos Ayala-Calvo e Alexandre José Schumacher. Todos os autores trabalharam juntos na redação e revisão final do manuscrito. 